\title{
Interlingual interference in a color-naming task'
}

\author{
E. C. DALRYMPLE-ALFORD \\ AMERICAN UNIVERSITY OF BEIRUT, LEBANON
}

When bilinguals, presented with lists of words written in different colors, name the colors as quickly as possible, interference with color naming has been found to depend on the semantic similarity between the words and the correct response, whether these come from the same or from different languages. However, in the present study, when the interference word was the translation of the correct response interference was greatly reduced, a result not attributable to overt translation. An explanation in terms of a 'priming' effect is suggested.

Interlingual interference arises from competition between the bilingual's two languages when he is attempting to use only one. A useful procedure for studying some aspects of such interference is the Stroop test (cf., Jensen \& Rohwer, 1966) in which $S$ is presented with color names written in noncongruent colors (e.g., RED written in green ink) and has to name the color of the ink as quickly as possible while ignoring the word written. Performance under these conditions is decidedly inferior to that under the control where the colors appear, for instance, as Xs. In the interlingual version of the task the words written are in one of the bilingual's languages while he names the colors in the other. The fact that color-naming performance is adversely affected whether the interference comes from the same or a different language as the response (Preston, 1965; Dalrymple-Alford \& Budayr, 1966) contradicts the view that when the bilingual is operating in one language the other is "blocked" or "switched off." Further, an explanation in terms of "attenuation" (cf., Treisman, 1960) instead of complete blocking of the interference language is inadequate, for the data of the studies cited show that interlingual interference is not very often less than intralingual interference. It is suggested here that the distinction between the bilingual's languages is a formal linguistic one and that from a psycholinguistic standpoint he should be considered as possessing a single linguistic system. Accordingly there should be no essential difference between inter- and intralingual interference in the Stroop test. Consequently we would expect the positive relationship noted by Klein (1964) between interference and the semantic similarity between interfering and response words, whether these are from the same language or not. This is borne out by the results of Preston (1965) in which non-color words were found to interfere less with responding than did color names, irrespective of the language membership (English and French) of the interference and the response. Further confirmation was obtained by the present writer in an unpublished study using Arabic and English. In the experiments reported here the extreme case was examined in which response and interference belonged to different languages but were identical in meaning, i.e., were translation-equivalents. Maximal interference was expected under these conditions.

\section{Method}

There were four conditions in Experiment 1. Six 20-item lists were prepared for each of these. The Control lists (X) consisted of triple $\mathrm{Xs}$ written in red, green, blue, black, and yellow inks. The lists for Condition CW ("color-word") consisted of the English words "red," "green," "blue," "black," and "yellow" written in the five different colors, but the color-word combinations were noncongruent. The M ("matching") condition lists had the same five English color names but these matched the color of the inks in which they were written (e.g., "red" in red ink). For the remaining condition, $N$ ("'noncolor word"), the lists consisted of the English words "home," "clay," "ship," "book," and "dog" written in the same five colors as the other lists.

In Experiment 2 the $M$ lists were replaced by HM ('half-matching") lists derived from the $M$ lists by replacing half of the items with noncongruent colorword combinations of the sort comprising the $\mathrm{CW}$ lists. The arrangment of the two types of items in these lists was random with the constraint that not more than two items of the same type occurred consecutively.

The 24 lists in each experiment were presented in counterbalanced order to the $S$, who was instructed to name the colors of the inks as quickly as possible in Arabic. Performance was tape recorded and later timed and examined for errors. In each experiment 11 male and 11 female Arabic-English bilingual university students acted as Ss.

\section{Results and Discussion}

It was expected that the best performance would be under the control condition, $\mathrm{X}$, followed by performance under the condition in which the interference was from non-color words $(\mathrm{N})$, then performance on the noncongruent color-word combinations (CW). The worst performance was expected when the interference words were translations of the correct responses (Condition M), for here the semantic similarity between the response and interference was greatest. The HM lists consisted equally of $\mathrm{M}$ and $\mathrm{CW}$ items 
Table 1. Mean color naming times in seconds.

\begin{tabular}{llcccc} 
& \multicolumn{6}{c}{ Conditions } \\
& \multicolumn{1}{c}{$\mathrm{X}$} & $\mathrm{N}$ & $\mathrm{CW}$ & $\mathrm{HM}$ & $\mathrm{M}$ \\
\cline { 2 - 6 } Exp. 1 & $12.81(9)$ & $15.39(7)$ & $18.89(21)$ & - & $15.50(8)$ \\
Exp. 2 & $12.41(11)$ & $14.73(6)$ & $17.19(19)$ & $16.30(17)$ & - \\
\hline
\end{tabular}

$\%$ errors given in brackets

and, consequently, performance was expected to be midway between that on those two types of list.

Table 1 sets out the mean color naming times and percentage errors for both experiments. After separate analyses of variance for the two sets of data showed a significant difference between conditions ( $\mathrm{F}>50, \mathrm{df}=3 / 60, \mathrm{p}<.001$ in both cases), the Newman-Keuls procedure was used to make multiple comparisons between the means. In Experiment 1, apart from the difference between $N$ and $M(p>.05)$, all differences were significant $(p<.01)$. In Experiment 2 the $\mathrm{CW}-\mathrm{HM}$ difference was significant beyond the $5 \%$ level and all other differences were significant beyond the $1 \%$ level.

While color-naming times for Conditions $\mathrm{X}, \mathrm{N}$, and $C W$ support the view that interlingual interference is a function of the semantic similarity of the interference and response words, the results for the $M$ and HM conditions are clearly contrary to expectations. When the interfering words are translation-equivalents of the correct responses, interference is not maximal though semantic similarity is greatest. Could it be that the Ss were translating the words of the $M$ lists instead of naming the colors of the inks? The mixture of congruent and noncongruent color-word combinations of the HM lists were intended to discourage this, but performance on these lists too was better than that on the CW lists. In any case the translation strategy would lead to faster responding only if translation is a speedier process than color-naming. This does not appear to be so. Seven additional Ss were asked to name the colors in the control lists (X) in Arabic, but to translate (into Arabic) the color names in the $\mathrm{CW}$ and $M$ lists. Mean times to complete the tasks $(\mathrm{N}=42)$ were $12.73 \mathrm{sec}$ for naming the colors in the control lists, and 19.38 and 20.33 sec for translating the words in the $\mathrm{M}$ and $\mathrm{CW}$ lists, respectively. (The translation times were not significantly different.)
A comparison of these figures with those in Table 1 makes the translation explanation untenable, and we conclude that the data reflect less interference with color naming in the case of the $M$ and HM lists.

If interference is a function of semantic similarity between interference and response words, how may we account for the reduction in interference when these words are translation-equivalents? One possibility is that perception of a word "primes" all words associatively related to it, in the sense that these words become more readily available for emission as responses. The degree of priming is assumed to be a function of the degree of association between the perceived and primed words. For the bilingual, translation-equivalents are likely to be strongly associated, and, consequently, perception of one is likely to lead to the priming of the other. When the primed word is identical to the response, responding is facilitated. Thus in the case of the M lists (and half the items in the HM lists), while the English color name delays responding because it has to be suppressed, it facilitates responding by priming its translation which is the correct response. In conclusion it may be noted that the hypothesized priming effect would account for Langer \& Rosenberg's (1966) finding that color naming when the items are nonsense syllables is facilitated when the syllables are those which tend to evoke the names of the colors in which they are written.

\section{References}

DALRYMPLE-ALFORD, E. C., \& BUDAYR, B. Examination of some aspects of the Stroop Color-Word test. Percept. mot. Skills., 1966, $23,1211-1214$.

JENSEN, A. R., \& ROHWER, W. D. The Stroop Color-Word test: a review. Acta Psychol., 1966, 25, 36-93.

KLEIN, G. S. Semantic power measured through the interference of words with color-naming. Amer. J. Psychol,, 1964, 77, 576-588.

LANGER, J., \& ROSENBERG, B. G. Symbolic meaning and color naming. J. Pers. Soc. Psychol., 1966, 4, 364-373.

PRESTON, M. S. Interlingual interference in a bilingual version of the Stroop Color-Word task. Unpublished Ph. D. thesis. McGill University, 1965.

TREISMAN, A. M. Contextual cues in selective listening. Quart. J. exp. Psychol., 1960, 12, 242-248.

Note

1. This study was supported by a grant from the Arts and Sciences Research Committee of the American University of Beirut. The data were collected by Assador Choungorian and Bushra Budayr and analyzed with the assistance of the latter and Arwa Aamiry to whom I am also grateful for comments on a preliminary draft of this paper. 